\title{
Serum Vaspin Concentrations Are Decreased after Exercise-Induced Oxidative Stress ${ }^{\ddagger}$
}

\author{
Andreas Oberbach $^{\mathrm{a}^{*}} \quad$ Katharina Kirsch $^{\mathrm{a}^{*}} \quad$ Stefanie Lehmann $^{\mathrm{a}} \quad$ Nadine Schlichting $^{\mathrm{a}}$ \\ Mathias Fasshauer ${ }^{\mathrm{a}} \quad$ Kim Zarse $^{\mathrm{b}} \quad$ Michael Stumvoll $^{\mathrm{a}}$ Michael Ristow ${ }^{\mathrm{b}}$ Matthias Blüher ${ }^{\mathrm{a}}$ \\ Peter Kovacs ${ }^{\mathrm{C}}$ \\ ${ }^{a}$ Department of Medicine, University of Leipzig, Leipzig, \\ ${ }^{\mathrm{b}}$ Department of Human Nutrition, Institute of Nutrition, University of Jena, Jena, \\ ${ }^{c}$ Interdisciplinary Centre for Clinical Research, Faculty of Medicine, University of Leipzig, Leipzig, Germany
}

\section{Keywords}

Obesity - Type 2 diabetes · Vaspin - Exercise .

Antioxidants · Oxidative stress · Insulin sensitivity

\section{Summary}

Elevated visceral adipose tissue-derived serpin (vaspin) serum concentrations are associated with impaired insulin sensitivity, but increase unexpectedly after long-term physical training. We therefore investigated the effect of an acute exercise bout and the effects of vitamin supplementation on chronic exercise effect and on serum vaspin concentrations. We measured serum vaspin and thiobarbituric acid-reactive substances (TBARS) concentrations in 80 individuals before and after a 1-hour acute exercise bout and independently in 40 healthy young men who were randomly assigned to either antioxidant (vitamin C $(1,000 \mathrm{mg} /$ day) and vitamin E (400 IU/day)) or to no supplementation after a standardized 4-week physical training program as a post hoc analysis. Serum vaspin concentrations significantly decreased after acute physical exercise as well as after 4 weeks of training in individuals without antioxidants. Changes in vaspin serum concentration correlate with increased TBARS serum concentrations both in response to a 1-hour exercise bout $(r=-0.42$, $p<0.01)$ and to the 4-week training $(r=-0.31, p<0.05)$. Interestingly, supplementation with antioxidants rather increased circulating vaspin levels in response to 4 weeks of exercise. In conclusion, vaspin serum concentrations are decreased by exercise-induced oxidative stress, but not by exercise-associated improvement in insulin sensitivity.

*These authors contributed equally to the work

${ }^{\ddagger}$ ClinicalTrials.gov registration number: NCT00638560

\section{Introduction}

Visceral adipose tissue-derived serpin (vaspin) was identified as an adipokine with insulin-sensitizing effects, which is predominantly secreted from visceral adipose tissue in a rat model of type 2 diabetes [1]. We recently reported that elevated vaspin serum concentrations are associated with obesity and impaired insulin sensitivity [2, 3]. Surprisingly, we also found that 4 weeks of physical exercise lead to increased vaspin serum concentrations. Exercise-related increase in circulating vaspin was significantly associated with decreased BMI, but also with BMI-independent improvement in insulin sensitivity and in fitness level. We therefore hypothesize that increased vaspin serum concentrations are directly related to the insulin-sensitizing effects of physical activity. To further elucidate the putative effects of physical exercise on circulating vaspin, we investigated vaspin serum concentrations in response to two different exercise interventions. We measured circulating vaspin before and after $1 \mathrm{~h}$ of resistance circle training as well as before and after a 4-week exercise intervention in healthy young men, who had been randomly assigned to groups with or without antioxidants supplementation as previously described [4], to elucidate the potential role of exercise-induced reactive oxygen species (ROS) in modulating circulating vaspin in humans.

\section{Material and Methods}

Acute Exercise Bout

80 healthy males (age $25 \pm 2.8$ years) were assigned to groups of athletes $(\mathrm{n}=20)$, previously trained $(\mathrm{n}=20)$ and untrained lean $\left(\mathrm{BMI}<23 \mathrm{~kg} / \mathrm{m}^{2}\right)$ $(\mathrm{n}=20)$ or obese $\left(\mathrm{BMI}>30 \mathrm{~kg} / \mathrm{m}^{2}\right)(\mathrm{n}=20)$ subjects, based on selfreported physical activity and on the data of a 1-hour resistance circuit

\section{KARGER}

Fax +497614520714

Information@Karger.de

www.karger.com (c) 2010 S. Karger GmbH, Freiburg

Accessible online at:

www.karger.com/ofa
Prof. Dr. med. Matthias Blüher

Department of Medicine, Faculty of Medicine ,University of Leipzig

Liebigstr 20,04103 Leipzig, Germany

Tel. +49 341 97-15984, Fax -22439

bluma@medizin.uni-leipzig.de 
Table 1. Baseline characteristics of the participants in the 1-hour exercise bout study

\begin{tabular}{lllll}
\hline & Athletes & $\begin{array}{l}\text { Previously trained } \\
\text { lean }\end{array}$ & $\begin{array}{l}\text { Previously untrained } \\
\text { lean }\end{array}$ & $\begin{array}{l}\text { Previously untrained } \\
\text { obese }\end{array}$ \\
\hline Number/sex & $20 /$ male & $20 /$ male & $20 /$ male & $20 /$ male \\
Age, years & $25.7 \pm 3.5$ & $23.4 \pm 3.2$ & $24.8 \pm 2.8$ & $23,9 \pm 1.9$ \\
BMI, $\mathrm{kg} / \mathrm{m}^{2}$ & $23.4 \pm 1.8$ & $23.1 \pm 1.7$ & $23.7 \pm 3.2$ & $31.4 \pm 0.8^{\mathrm{a}, \mathrm{b}, \mathrm{c}}$ \\
Fat mass, \% & $12.1 \pm 2.2$ & $15.5 \pm 2.8$ & $17.2 \pm 3.1^{\mathrm{a}}$ & $28.7 \pm 10.1^{\mathrm{a}, \mathrm{b}, \mathrm{c}}$ \\
Fat free mass, $\mathrm{kg}$ & $69.2 \pm 6.1$ & $65.6 \pm 3.3$ & $64.8 \pm 8.7$ & $61.7 \pm 9.2$ \\
VO2 max, ml/min/kg & $54.0 \pm 4$ & $52.8 \pm 5.1$ & $47.7 \pm 5.8^{\mathrm{a}}$ & $33.8 \pm 7.9^{\mathrm{a}, \mathrm{b}, \mathrm{c}}$ \\
TBARS, pmol/1 & $1.8 \pm 0.3$ & $1.7 \pm 0.5$ & $1.6 \pm 0.6$ & $1.7 \pm 0.5$ \\
\hline
\end{tabular}

${ }^{\mathrm{a}} \mathrm{p}<0.05$ compared to athletes.

${ }^{\mathrm{b}} \mathrm{p}<0.05$ compared to previously trained lean.

c $<<0.05$ compared to previously untrained lean.
Table 2. Effects of antioxidant supplementation on anthropometric and circulating parameters $($ mean $\pm \mathrm{SD})$

\begin{tabular}{|c|c|c|c|c|}
\hline & \multicolumn{2}{|c|}{ No supplements } & \multicolumn{2}{|c|}{ VitaminC / vitamin E } \\
\hline & baseline & 4 weeks & baseline & 4 weeks \\
\hline Number/sex & 20/male & 20/male & 20/male & 20/male \\
\hline Age & $26.1 \pm 3.6$ & - & $26.7 \pm 2.7$ & - \\
\hline $\mathrm{BMI}, \mathrm{kg} / \mathrm{m}^{2}$ & $24.3 \pm 2.1$ & $24.2 \pm 2$ & $23.7 \pm 1.7$ & $23.5 \pm 1.8$ \\
\hline Fat mass, $\%$ & $13.9 \pm 4.5$ & $15.1 \pm 4.4$ & $11.4 \pm 6.4$ & $11.9 \pm 5.6$ \\
\hline $\mathrm{VO} 2 \mathrm{max}, \mathrm{ml} / \mathrm{min} / \mathrm{kg}$ & $50.1 \pm 6.9$ & $50.8 \pm 6.4$ & $50 \pm 7.8$ & $51.6 \pm 7.6$ \\
\hline FPG, $\mathrm{mmol} / \mathrm{l}$ & $5.1 \pm 0.8$ & $4.7 \pm 0.3$ & $4.9 \pm 0.9$ & $4.6 \pm 0.6$ \\
\hline FPI, pmol/l & $14.8 \pm 7.2$ & $10.9 \pm 5.6^{*}$ & $10.5 \pm 6.3^{\#}$ & $10.8 \pm 5.4$ \\
\hline $\mathrm{GIR}, \mu \mathrm{mol} / \mathrm{kg} / \mathrm{min}$ & $108 \pm 14$ & $116 \pm 12 * \#$ & $110 \pm 12$ & $111 \pm 11$ \\
\hline Leptin, ng/ml & $4.2 \pm 2.5$ & $4.2 \pm 2.2$ & $3.7 \pm 2.9$ & $3.7 \pm 2.6$ \\
\hline Adiponectin, $\mathrm{ng} / \mathrm{ml}$ & $13.9 \pm 4.4$ & $17.4 \pm 4.2^{* \#}$ & $13.6 \pm 3.9$ & $13 \pm 3.5$ \\
\hline TBARS, pmol/1 & $1.7 \pm 0.5$ & $1.9 \pm 0.7$ & $1.8 \pm 0.6$ & $1.5 \pm 0.5$ \\
\hline
\end{tabular}

FPG $=$ Fasting plasma glucose; FPI $=$ fasting plasma insulin; GIR = glucose infusion rate during the steady state of an euglycemic-hyperinsulinemic clamp; TBARS = thiobarbituric acid-reactive substances.

$* \mathrm{p}<0.05$ for between group comparisons after 4 weeks.

$* \mathrm{p}<0.05$ comparing data before and after 4 weeks of exercise within treatment groups.

\# $\mathrm{p}<0.05$ comparing the no supplements with the vitamin $\mathrm{C} /$ vitamin E group. training at $80 \%$ of individual maximal power (table 1 ). The training session consisted of three repetitions at ten different stations. Before, immediately after, and after 24 and $48 \mathrm{~h}$, blood samples were taken.

\section{Long-Term Antioxidant Supplementation Study}

Forty healthy males participated in a prospectively randomized 4-week intensive training intervention as previously described [4] (table 2). Randomization was stratified according to gender, age and BMI. Computerassisted randomization was performed centrally at the University of Leipzig Clinical Data Center using Pocock's minimization algorithm. The study design has been previously reported [4]. Insulin sensitivity was assessed with the euglycemic-hyperinsulinemic clamp method as already described [4]. Measurement of circulating vaspin represents a post hoc analysis of the previously reported trial [4]. Participants were randomized into an antioxidant treatment $(\mathrm{n}=20)$ and a placebo control group $(\mathrm{n}=20)$. Participants in the antioxidant treatment group received 1,000 $\mathrm{mg}$ vitamin $\mathrm{C}$ (Ascorbic Acid; Jenapharm, Jena, Germany) and $400 \mathrm{IU}$ vitamin E (RRR-/D- $\alpha$-tocopherol; Jenapharm) per day orally. Monitoring of vitamin $\mathrm{C}$ and/or vitamin $\mathrm{E}$ kinetics was not an objective of this study. Compliance with daily vitamin supplementation was checked at every training session by counting the remaining tablets. To evaluate oxidative stress, we measured serum concentrations of thiobarbituric acid- reactive substances (TBARS) as described previously [4]. All individuals were subjected to supervised physical training which consisted of training sessions on 5 consecutive days of the week for 4 weeks. Each session included 20 min of biking or running, 45 min of circuit training and 20-min periods for warming up and cooling down. All individuals completed a graded bicycle ergometer test and trained at their individual submaximal heart rate. At baseline and after 4 weeks of training blood samples were obtained 3 days after the last acute exercise bout between 8-10 a.m. after an overnight fast. The present study was approved by the ethics committee of the University of Leipzig, Leipzig, Germany. Study participants gave written informed consent before initiation of the study. The study design was registered at ClinicalTrials.gov registration number NCT00638560. Measurement of vaspin serum concentrations was performed using an ELISA as described [2]

\section{Statistical Analyses}

Statistical analyses were performed with SPSS, Version 15.0 (SPSS, Chicago, IL, USA). Group comparisons were made using two-sided unpaired Student's $t$ test for the antioxidant supplementation study and using ANOVA for the acute exercise bout study. Sample size was calculated to achieve a power of $90 \%$ at a significance level of $5 \%$ using the program nQuery Advisor ${ }^{\circledR} 6.0$ (STATCON, Witzenhausen, Germany). 

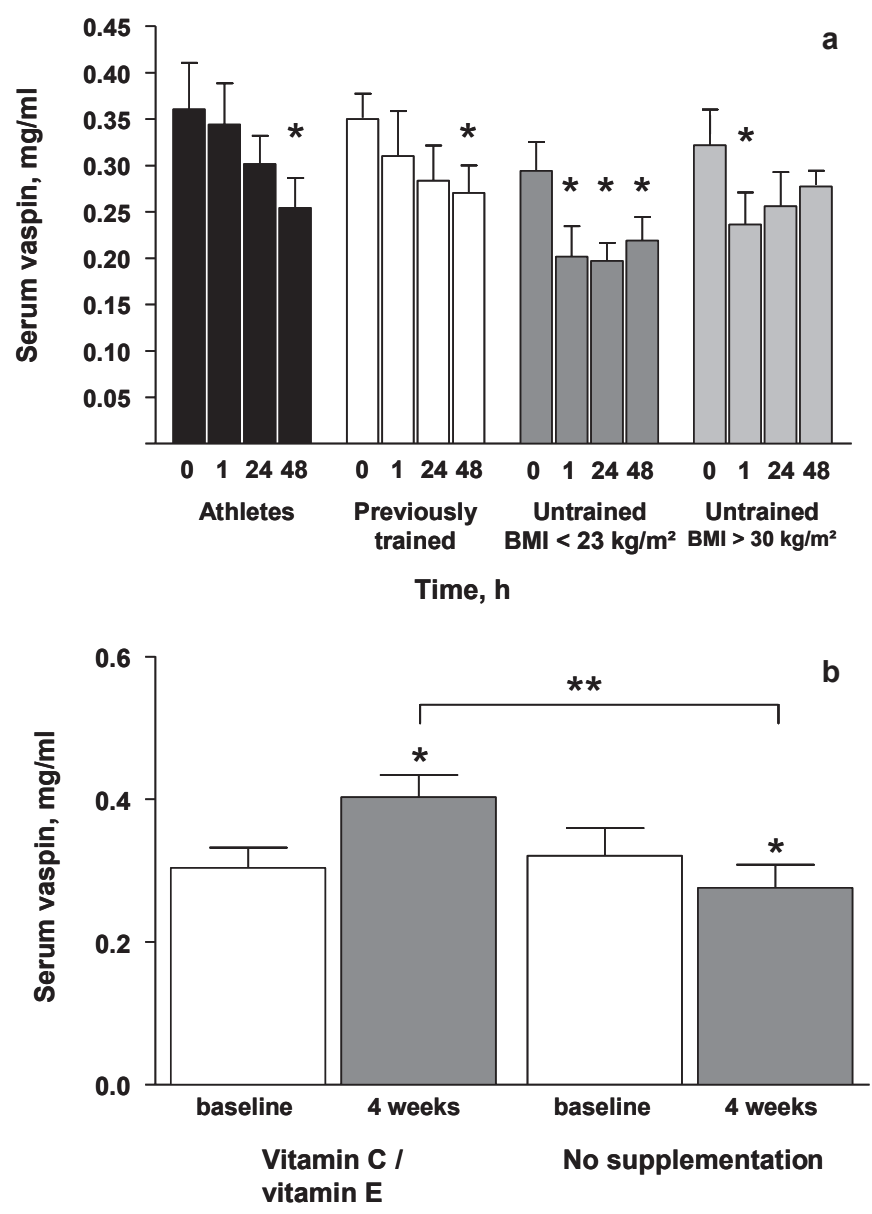

Fig. 1. Effects of exercise training on vaspin serum concentrations. a Effect of 60 -min resistance circuit training at $80 \%$ of individual maximal power on vaspin serum concentrations in 80 healthy young (age $25 \pm 2.8$ years) males. Circulating vaspin in groups of athletes, previously trained and untrained lean $\left(\mathrm{BMI}<23 \mathrm{~kg} / \mathrm{m}^{2}\right)$ or obese $\left(\mathrm{BMI}>30 \mathrm{~kg} / \mathrm{m}^{2}\right)$ (each group, $\mathrm{n}=20$ ) before, immediately (i.e. time point $1 \mathrm{~h}$ ), 24 and $48 \mathrm{~h}$ after the training session. b Vaspin serum concentrations before and after 4-week exercise training intervention in individuals without (no supplement., $\mathrm{n}=20$ ) or with antioxidant supplementation (vitamin $\mathrm{C} / \mathrm{vita}$ min $E, n=20)$. At baseline and after 4 weeks of training blood samples were obtained 3 days after the last acute exercise bout between 8-10 a.m. after an overnight fast. Participants in the antioxidant treatment group received 1,000 $\mathrm{mg}$ vitamin $\mathrm{C}$ (ascorbic acid, Jenapharm) and $400 \mathrm{IU}$ vitamin E (RRR-/D- $\alpha$-tocopherol, Jenapharm) per day orally. Data are means \pm SEM

$* \mathrm{p}<0.05$ compared to baseline. Bracket indicate significant different vaspin serum concentration after 4 weeks training between individuals with or without antioxidant treatment $(* * \mathrm{p}<0.01)$.

\section{Results}

Baseline characteristics of individuals participating in the 1-hour exercise bout study are given in table 1. Short-term physical exercise caused decreased vaspin serum concentrations, which became significant compared to baseline at different time points depending on the subjects' training status (fig. 1a). Baseline circulating vaspin was not significantly different between groups of athletes, previously trained and un- trained lean $\left(\mathrm{BMI}<23 \mathrm{~kg} / \mathrm{m}^{2}\right)$ or obese $\left(\mathrm{BMI}>30 \mathrm{~kg} / \mathrm{m}^{2}\right)$ healthy young men. In the long-term antioxidant supplementation study, we have previously shown that exercise increases parameters of insulin sensitivity (glucose infusion rate (GIR) during euglycemic-hyperinsulinemic clamp and plasma adiponectin concentration) only in the absence of antioxidants. The effects of antioxidant supplementation on additional parameters are shown in table 2. To evaluate oxidative stress, we measured serum concentrations of TBARS, a well-established marker of overall oxidative stress reflecting oxidized lipids, a known stable intermediate of ROS formation in mammals [5]. Both acute exercise (baseline $1.7 \pm 0.4 \mathrm{pmol} / \mathrm{l}$; after exercise bout $2.8 \pm 0.6 \mathrm{pmol} / \mathrm{l}$ ) and the 4-week training program (table 2) caused increased TBARS serum concentrations. Antioxidant supplementation resulted in lower TBARS serum concentrations, although this did not reach statistical significance (table 2). However, we observed a more than two-fold increase in skeletal muscle TBARS levels following physical exercise in the absence of antioxidants, whereas individuals taking antioxidant supplements showed no significant increase in both circulating and skeletal muscle TBARS concentrations after exercise [4]. This was paralleled by increased mRNA expression of ROS-sensitive transcriptional regulators of insulin sensitivity and ROS defense capacity such as peroxisome proliferator-activated receptor- $\gamma(\operatorname{PPAR} \gamma)$ and PPAR $\gamma$ coactivators PGC1 $\alpha$ and PGC1 $\beta$ only in the absence of antioxidants [4]. Molecular mediators of endogenous ROS defense (superoxide dismutases 1 and 2; glutathione peroxidase) were also induced by exercise, and this effect was blocked by antioxidant supplementation [4]. After the 4-week training program in the long-term antioxidant supplementation study, we observed a significant decrease in vaspin serum concentrations $(p<0.05)$. In contrast, individuals who received antioxidants exhibited a significant increase in circulating vaspin (fig. 1b). At baseline, there was no correlation between vaspin and TBARS serum concentrations. However, changes in vaspin serum concentration negatively correlated with increased TBARS serum concentrations both in response to a 1-hour exercise bout $(\mathrm{r}=-0.42, \mathrm{p}<0.01)$ and to the 4-week training $(\mathrm{r}=-0.31, \mathrm{p}<0.05)$. The correlation in the 4-week training study remained significant after adjusting for age, gender and changes in BMI. Additional inclusion of training-induced changes in GIR as a covariate in the multivariate model abolished the significant correlation between changes in vaspin and TBARS serum concentrations. There were no adverse events or side effects associated with the acute exercise bout and the long-term antioxidant supplementation study [4].

\section{Discussion}

Lower vaspin serum concentrations have been a consistent finding in lean, insulin sensitive compared to obese individuals $[2,3,6,7]$. We recently found a significant negative rela- 
tionship between circulating vaspin and GIR during the steady state of an euglycemic-hyperinsulinemic clamp [2]. However, we observed an unexpected increase in vaspin serum concentrations after a 4 -week exercise training program [2], which positively correlated with an improvement of insulin sensitivity. The aim of this study was therefore to elucidate mechanisms beyond the association between circulating vaspin and insulin sensitivity that could explain the paradoxical regulation of vaspin serum concentrations, specifically in relation to exercise. Physical exercise exerts numerous health-promoting effects including improvement of insulin sensitivity [8]. These effects may be independent of exerciserelated changes in body mass [9]. In response to physical exercise, skeletal muscle generates ROS, which may mediate some of the health-promoting effects of exercise $[4,10,11]$. Here we demonstrate that the previously shown increased oxidative stress following physical exercise [4] leads to reduced vaspin serum concentrations immediately after the training session, with sustained lower circulating vaspin $48 \mathrm{~h}$ after an acute exercise bout. To evaluate oxidative stress, we measured serum concentrations of TBARS, a known stable intermediate of ROS formation in mammals and a well-established marker of overall oxidative stress reflecting oxidized lipids [5]. Noteworthy, there was a correlation between vaspin and TBARS serum concentrations at baseline. To further elucidate the effects of oxidative stress on circulating vaspin, we compared vaspin levels in young and healthy men after 4 weeks of an intensive exercise training program in the presence or absence of antioxidant treatment. In individuals without antioxidant supplementation, we found significantly lower circulating vaspin after 4 weeks of training consistent with the recently reported significant improvement in insulin sensitivity [4]. In contrast, in individuals who received antioxidants during the 4-week training, vaspin serum concentrations were found to be significantly increased. This latter finding in the antioxidant supplementation group supports our previous finding that physical exercise increases insulin sensitivity by induction of ROS in humans [4]. Interestingly, there was a significant negative correlation between training-associated changes in vaspin and TBARS serum concentrations. However, this relationship did not remain significant after adjusting for traininginduced changes in insulin sensitivity (GIR). We can therefore not distinguish whether improved insulin sensitivity or increased oxidative stress in response to the 4-week training program is the predominant cause or predictor of decreased vaspin serum concentration. The recently reported increased vaspin serum concentrations after a 4-week training intervention in patients with type 2 diabetes, normal and impaired glucose tolerance [2] either suggest that patients in the previous study had unrecognized antioxidant supplementation or that the previously reported training intensity was not sufficient to chronically increase oxidative stress.

In conclusion, our results demonstrate that increased oxidative stress following short- and long-term physical training decreases vaspin serum concentration, whereas changes in insulin sensitivity do not seem to regulate circulating vaspin.

\section{Acknowledgements}

This work was supported by grants from the Deutsche Forschungsgemeinschaft (DFG) KO 3880/1-1 (to PK), the Clinical Research Group 'Atherobesity' KFO 152 (project BL 833/1-1) (MB) and project FA 476/4-1 (MF).

\section{Disclosure}

The authors declared no conflict of interest.

\section{References}

1 Hida K, Wada J, Eguchi J, Zhang H, Baba M, Seida A, Hashimoto I, Okada T, Yasuhara A, Nakatsuka A, Shikata K, Hourai S, Futami J, Watanabe E, Matsuki Y, Hiramatsu R, Akagi S, Makino $\mathrm{H}$, Kanwar YS: Visceral adipose tissue-derived serine protease inhibitor: A unique insulin-sensitizing adipocytokine in obesity. Proc Natl Acad Sci U S A 2004;102:10610-10615.

2 Youn BS, Klöting N, Kratzsch J, Lee N, Park JW, Song ES, Ruschke K, Oberbach A, Fasshauer M Stumvoll M, Blüher M: Serum vaspin concentrations in human obesity and type 2 diabetes. Diabetes 2008;57:372-377.

3 Klöting N, Berndt J, Kralisch S, Kovacs P, Fasshauer M, Schön MR, Stumvoll M, Blüher M Vaspin gene expression in human adipose tissue: association with obesity and type 2 diabetes. Biochem Biophys Res Commun 2006;339:430-436.
4 Ristow M, Zarse K, Oberbach A, Klöting N, Birringer M, Kiehntopf M, Stumvoll M, Kahn CR, Blüher M: Antioxidants prevent health-promoting effects of physical exercise in humans. Proc Natl Acad Sci U S A 2009;106:8665-8670.

5 Yagi K (ed): Lipid Peroxides in Biology and Medicine. New York, Academic Press, 1982, pp 223-242.

6 Handisurya A, Riedl M, Vila G, Maier C, Clodi M, Prikoszovich T, Ludvik B, Prager G, Luger A, Kautzky-Willer A: Serum vaspin concentrations in relation to insulin sensitivity following RYGBinduced weight loss. Obes Surg 2009;17:1184-1188.

$\checkmark 7$ Suleymanoglu S, Tascilar E, Pirgon O, Tapan S, Meral C, Abaci A: Vaspin and its correlation with insulin sensitivity indices in obese children. Diabetes Res Clin Pract 2009;84:325-328.
8 Warburton DE, Nicol CW, Bredin SS: Health benefits of physical activity: the evidence. CMAJ 2006;174:801-809.

9 Duncan GE, Perri MG, Theriaque DW, Hutson $\mathrm{AD}$, Eckel RH, Stacpoole PW: Exercise training, without weight loss, increases insulin sensitivity and postheparin plasma lipase activity in previously sedentary adults. Diabetes Care 2003;26:557-562.

10 Powers SK, Jackson MJ: Exercise-induced oxidative stress: cellular mechanisms and impact on muscle force production. Physiol Rev 2008;88: 1243-1276.

11 Kelley DE, Goodpaster BH: Effects of exercise on glucose homeostasis in type 2 diabetes mellitus. Med Sci Sports Exerc 2001;33(suppl 6):S495-S501. 